\title{
Management of spine fractures in ankylosing spondylitis and diffuse idiopathic skeletal hyperostosis: a challenge
}

\author{
Maximilian Schwendner, MD, ${ }^{1,2}$ Martin Seule, MD, ${ }^{3}$ Bernhard Meyer, MD, ${ }^{1}$ and \\ Sandro M. Krieg, MD, MBA ${ }^{1,2}$
}

${ }^{1}$ Department of Neurosurgery and ${ }^{2}$ TUM Neuroimaging Center, Technical University of Munich, School of Medicine, Klinikum rechts der Isar, Munich, Germany; and ${ }^{3}$ Department of Neurosurgery, Kantonsspital St. Gallen, Switzerland

\begin{abstract}
OBJECTIVE Ankylosing spinal disorders (ASDs) such as ankylosing spondylitis (AS) and diffuse idiopathic skeletal hyperostosis (DISH) are complex diseases regarding diagnostics, treatment, and patient outcome, especially in trauma. Originating from rigid biomechanics and low bone quality in considerably comorbid patients, serious spinal injury requires thorough and immediate imaging and is frequently missed. The aim of this study was to evaluate patient characteristics as well as procedures in patients with ASD in order to identify the major particularities of treatment.
\end{abstract}

METHODS A total of 60 patients aged $78.5 \pm 8.9$ years were retrospectively included. Preoperative imaging as well as surgical treatment procedures and postoperative patient outcome were analyzed, including 30-day readmissions.

RESULTS CT imaging of the entire spine was performed within 24 hours after the initial trauma in $73.3 \%$ of patients. A delay in diagnostics ( $>24$ hours) occurred in $41.7 \%$ of patients transferred from primary care centers. At admission, $25.0 \%$ of patients had fracture-related neurological deficits (American Spinal Injury Association [ASIA] grades A and B in 4 patients, and ASIA grades $C$ and $D$ in 11 patients). A spinal epidural hematoma was found in $21.2 \%$ of patients and was symptomatic in $72.7 \%$ of those patients. Of the patients with fracture-related neurological deficits, $93.3 \%$ were operated on within 48 hours from symptom onset. One patient $(1.7 \%)$ developed neurological deficits from diagnosis to surgery. Postoperatively, $18.3 \%$ of patients had surgical complications, and $76.7 \%$ of patients developed further medical issues, with pneumonia $(38.3 \%)$, pulmonary decompensation $(25.0 \%)$, and cardiac decompensation $(20.0 \%)$ being the leading causes. The 30 -day mortality rate was high at $10.0 \%$.

CONCLUSIONS Treatment of patients with ASDs is complex. While surgical outcome is usually good, the multimorbid nature of these patients results in a high rate of major medical complications. If an ankylosing disease is suspected, MRI of the entire spine is mandatory. Upon diagnosis, treatment should be performed in centers capable of managing all aspects of the regular complications these patients will develop.

https://thejns.org/doi/abs/10.3171/2021.7.FOCUS21330

KEYWORDS spinal trauma; ankylosing spinal disorders; diffuse idiopathic skeletal hyperostosis

$\Lambda$ NKYLOSING spinal disorders (ASDs) such as ankylosing spondylitis (AS) and diffuse idiopathic skeletal hyperostosis (DISH) are complex diseases, especially when it comes to surgical treatment in cases of trauma.

AS is a seronegative systemic chronic rheumatic disease. It mainly manifests in the axial skeleton, especially the spine. It is characterized by disruption of bone architecture combined with osteoplastic changes. This results in osteoporosis of the spine with a further increased risk of fractures. ${ }^{1}$ As the disease progresses, complete stiffening of the spine occurs along with increased thoracal kyphosis and lumbar lordosis.

DISH is a skeletal disorder presented with skeletal hyperostosis such as abundant formations of bone, especially of the anterior longitudinal ligament, and is mostly found in male patients aged 50 years or older. ${ }^{2,3}$ It ultimately results in progressive stiffening of the spine, causing pain, stiffness, and dysphagia. ${ }^{4}$ While dual-energy x-ray absorptiometry often suggests higher bone mineral density (BMD), studies including quantitative CT have shown no increase in BMD in patients with DISH. ${ }^{4}$ Furthermore, pa-

ABBREVIATIONS AS = ankylosing spondylitis; ASA-PS = American Society of Anesthesiologists physical status; $A S D=$ ankylosing spinal disorder; ASIA = American Spinal Injury Association; BMD = bone mineral density; BMRC = British Medical Research Council; CPR = cardiopulmonary resuscitation; DISH = diffuse idiopathic skeletal hyperostosis.

ACCOMPANYING EDITORIAL DOI: 10.3171/2021.7.FOCUS21436.

SUBMITTED May 31, 2021. ACCEPTED July 16, 2021.

INCLUDE WHEN CITING DOI: 10.3171/2021.7.FOCUS21330. 


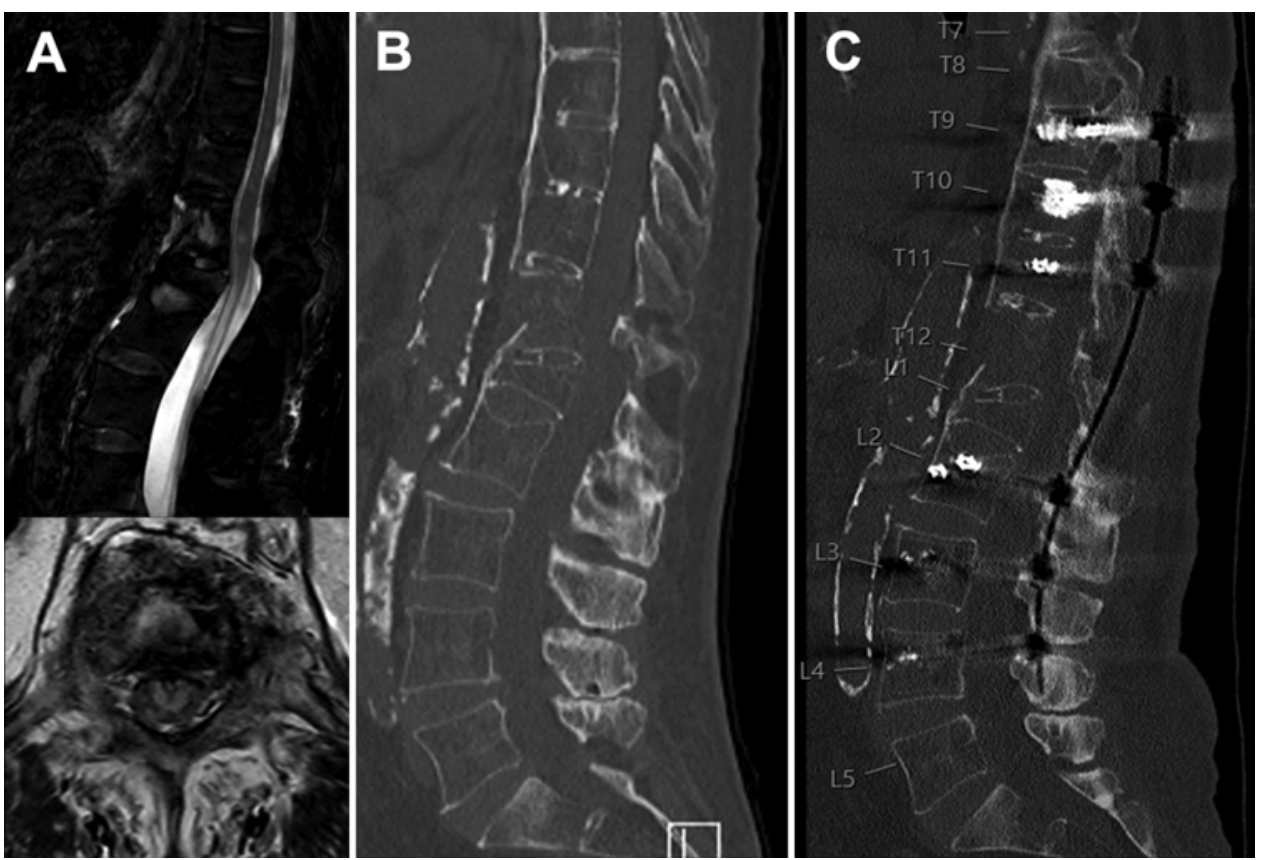

FIG. 1. Images obtained in a 78-year-old female with a medical history of AS. After a low-impact trauma, the patient suddenly felt intense back pain. At an external hospital, CT scans showed fractures of T12 and L1. Dorsal instrumentation with percutaneous cemented pedicle screws was performed. Preoperative MR images (A) as well as preoperative (B) and postoperative (C) CT scans are shown.

tients with low BMD and DISH are even more likely to incur vertebral fractures. ${ }^{4}$ Due to reduced flexibility and a strong cantilever in each direction, those patients experience fractures more frequently, and treatment requires longer constructs to address the long cantilevers.

In cases of trauma, diagnostics and treatment strategies in these patients are often unclear. A change in biomechanics of the ossified spine requires extensive diagnostics. Regarding treatment, patients show high complication rates as well as high mortality rates. However, fractures of
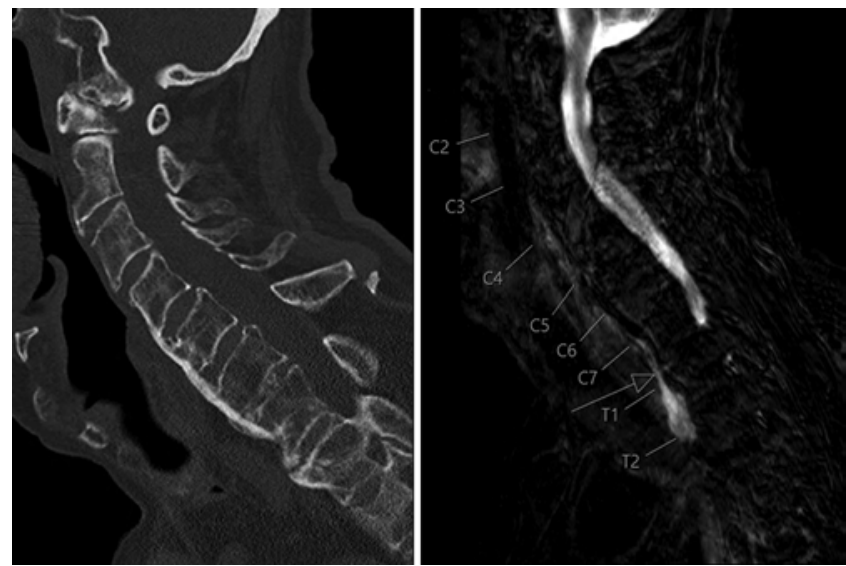

FIG. 2. Images obtained in a 95-year-old male with DISH of the cervical spine. On CT imaging (left), no clear fracture could be identified. An MR image (right) shows a prevertebral hematoma found at the cervicothoracic junction related to a fracture of the disc space between cervical vertebra 7 and thoracic vertebra 1. the spine in patients with AS and DISH are usually unstable fractures requiring surgical treatment. The aim of this study was to retrospectively evaluate patient characteristics, diagnostic procedures, and treatment strategies in patients with AS and DISH at our center.

\section{Methods}

\section{Ethics}

The study was approved by the local ethics board. We performed the study in accordance with the Declaration of Helsinki.

\section{Study Protocol}

Patients diagnosed with AS or DISH based on radiographs obtained between 2017 and 2021 were considered eligible for this study. Inclusion criteria were patients with AS or DISH and fractures of the spine who underwent surgical treatment at our institution. For all patients, fractures were classified in accordance with the $\mathrm{AO}$ classification. The time from trauma to diagnostics and surgical procedures, as well as patient characteristics and patient outcome, was analyzed. Clinical outcome was assessed with the American Spinal Injury Association (ASIA) Impairment Scale and the British Medical Research Council (BMRC) grading system.

\section{Radiographic Analysis}

Preoperative CT and MRI studies were analyzed regarding the time from trauma to imaging and fracturerelated parameters (Figs. 1 and 2). On CT imaging, data on the fracture classification, fractured level, and preva- 
lence of bone fragments were acquired. MRI studies were analyzed regarding fractures and ligament injuries as well as intraspinal and prevertebral hematoma (Fig. 2).

\section{Statistical Analysis}

Statistical analysis was performed using Prism version 8.4.1 (GraphPad Software). Descriptive statistics including mean, median, minimum, maximum, and standard deviation were calculated for patient- and fracture-related characteristics, including radiographic measurements.

\section{Results}

\section{Patient Characteristics}

Overall, 60 patients (14 female and 46 male) with 66 fractures of the cervical, thoracic, and lumbar spine were analyzed. The median ASA-PS (American Society of Anesthesiologists physical status) class was 3 (range 2-4). The leading symptom of all patients at presentation was pain, and $25.0 \%$ of patients exhibited fracture-related neurological deficits. The trauma mechanisms were mainly minor traumas such as falls from a standing or sitting position $(78.3 \%$ ) (Table 1). Hyperextension in trauma was documented in 20 patients and flexion in 10 patients, whereas in 30 patients a trauma mechanism remained unclear due to syncopal falls of an unclear course. Five patients (8.3\%) showed blood concentrations of alcohol at the time of the trauma. Fractures classified by the AO classification were $\mathrm{B} 3$ in $84.8 \%$ and $\mathrm{C} 1$ in $15.2 \%$. Accompanying injuries occurred in $48.3 \%$ of patients, mainly head wounds (Table 1). At admission, 33.3\% and 30\% of patients were on a regimen of antiplatelet agents and oral anticoagulation medications, respectively, and deranged international normalized ratio values and platelet counts were found in $18.3 \%$ of patients.

\section{Diagnostics}

CT imaging was performed within 24 hours after the initial trauma in $73.3 \%$ of patients (44 of 60). Twenty-four patients presented as a referral from a primary care hospital for further treatment. In 7 patients a delay of diagnostics of $14.3 \pm 20.6$ days (range 1-60 days) was due to patients initially reporting only minor pain and getting medical advice for other medical issues, an increase in pain severity, or, as in 1 patient, new neurological deficits. In $10(41.7 \%)$ of the 24 referred patients, overall diagnostics in the primary care hospitals were delayed by $8.8 \pm$ 5.6 days (range $2-17$ days), especially in patients who presented for other medical issues, mostly cardiopulmonary decompensation. In 8 patients (33.3\%), fractures were not correctly identified for $10.1 \pm 5.4$ days (range 4-17 days) and, therefore, not treated initially, and 2 patients $(8.3 \%)$ showed progressive neurological deficits before diagnostics were performed and the patients were referred to our center. In 1 patient (4.2\%), a thoracic fracture was diagnosed after admission to our institution due to another spinal fracture. On CT scans, fracture-related absolute spinal canal stenosis was diagnosed in 13 patients (Table 2). MRI was performed within 24 hours after admission (door to MRI) in $76.7 \%$ of patients (Fig. 3). In 9 of 66 $(13.6 \%)$ of the fractures, MRI was not performed preop-
TABLE 1. Patient data and risk factors

\begin{tabular}{|c|c|}
\hline & Value \\
\hline No. of pts & 60 \\
\hline No. of fractures & 66 \\
\hline \multicolumn{2}{|l|}{ Sex } \\
\hline $\mathrm{F}$ & $14(23.3)$ \\
\hline M & $46(76.7)$ \\
\hline Mean age at op (range), yrs & $78.5 \pm 8.9(55.2-94.9)$ \\
\hline \multicolumn{2}{|l|}{ Accompanying injuries } \\
\hline Head wound & $14(23.3)$ \\
\hline Traumatic brain injury & $6(10.0)$ \\
\hline Additional fractures & $10(16.7)$ \\
\hline Lower extremities & $5(8.3)$ \\
\hline Upper extremities & $1(1.7)$ \\
\hline \multicolumn{2}{|l|}{ Trauma impact } \\
\hline Major trauma & $11(18.3)$ \\
\hline Minor trauma* & $47(78.3)$ \\
\hline No trauma & $2(3.3)$ \\
\hline \multicolumn{2}{|l|}{ Trauma mechanism } \\
\hline Hyperextension & $20(33.3)$ \\
\hline Hyperflexion & $10(16.7)$ \\
\hline Unknown & $30(50.0)$ \\
\hline \multicolumn{2}{|l|}{ ASA-PS class } \\
\hline 1 & $0(0.0)$ \\
\hline II & $10(16.7)$ \\
\hline III & $42(70.0)$ \\
\hline IV & $8(13.3)$ \\
\hline Median ASA-PS class (range) & $3(2-4)$ \\
\hline \multicolumn{2}{|l|}{ AO fracture classification } \\
\hline B3 & $56(84.8)$ \\
\hline $\mathrm{C} 1$ & $10(15.2)$ \\
\hline \multicolumn{2}{|l|}{ Postop LOS, days } \\
\hline Mean (range) & $19.4 \pm 14.5(3-77)$ \\
\hline Median & 17 \\
\hline
\end{tabular}

LOS = length of stay; pts = patients.

Values represent the number of patients (\%) or mean \pm SD unless indicated otherwise. Both cohorts show a similar distribution of risk factors including the ASA-PS class and AO classification of fractures.

${ }^{*}$ Defined as trauma from a standing or sitting position.

eratively due to progressive neurological deficits and immediate surgery, or contraindications for routine MRI such as automatic implantable cardiac defibrillators. On MRI, all patients showed a rupture of the spinal ossified ligaments, and spinal epidural hematoma was found in 11 patients $(21.2 \%)$, with 8 of those $(72.7 \%)$ presenting with neurological deficits $(\mathrm{p}<0.001)$ (Table 2$)$.

\section{Surgical Data}

The timing of surgery was dependent on the patient's neurological status. Surgery was performed within 48 hours in all 15 patients with fracture-related neurological deficits except for 1 patient with ongoing symptoms for several days who was transferred from abroad. Overall, 
TABLE 2. Preoperative imaging and radiographic findings for the fractures

\begin{tabular}{cc}
\hline & No. of Cases $(\%)$ \\
\hline CT & $66(100)$ \\
\hline Intraspinal bony fragment & $13(19.7)$ \\
\hline Obtained <24 hrs from trauma & $45(68.2)$ \\
\hline MRI & $57(100)$ \\
\hline Disc rupture & $41(71.9)$ \\
\hline Prevertebral hematoma & $46(80.7)$ \\
\hline Epidural hematoma & $11(19.3)$ \\
\hline Anterior of spinal cord & $6(54.5)$ \\
\hline Posterior of spinal cord & $9(81.8)$ \\
\hline Preop neurological deficits & $8(72.7)$ \\
\hline Surgical decompression & $7(63.6)$ \\
\hline
\end{tabular}

surgery was performed $8.8 \pm 13.7$ days (range $0-86$ days) after the trauma and 5.6 \pm 8.0 days (range $0-35$ days) after admission to our institution for all 60 patients. One patient's condition deteriorated preoperatively, but bedrest was limited due to patient noncompliance.

Intraoperative cardiopulmonary decompensation required cardiopulmonary resuscitation (CPR) in 3 patients. One patient who required CPR in an initial, interrupted surgery also required CPR because of cardiac arrest in the second surgery for completion of the percutaneous pedicle screw construct.

Regarding surgical treatment of fractures of the thoracic and lumbar spine, dorsal instrumentation covering three vertebrae above and three vertebrae below the fractured level was performed in order to address the fairly long lever of the rigid spine. In one case of a fracture of the upper thoracic spine, an additional vertebral body replacement was performed due to excessive injury (Table 3 ).

In cases of a fracture of the cervical spine, dorsal in-

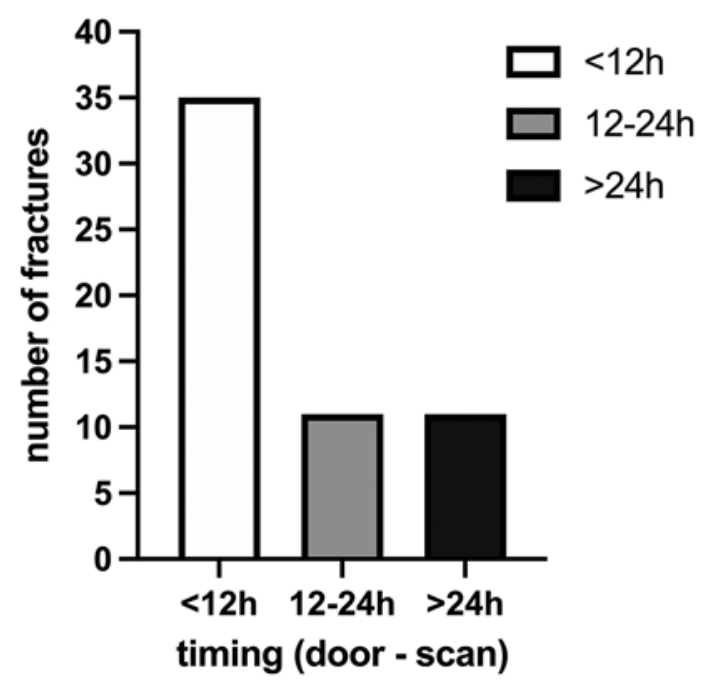

FIG. 3. Imaging time frames for all 57 fractures analyzed by MRI; $61.4 \%$ were performed within 12 hours.
TABLE 3. Fracture location and surgical treatment

\begin{tabular}{lccl}
\hline & \multicolumn{3}{c}{ No. of Cases (\%) } \\
\cline { 2 - 4 } & Cervical & Thoracic & Lumbar \\
\hline No. of fractures & $22(33.3)$ & $38(57.6)$ & $6(9.1)$ \\
\hline Anterior instrumentation & $5(22.7)$ & $1(2.6)$ & $0(0.0)$ \\
\hline Anterior instrumentation first & $2(9.1)$ & $0(0.0)$ & $0(0.0)$ \\
\hline Anterior instrumentation last & $3(13.6)$ & $1(2.6)$ & $0(0.0)$ \\
\hline Posterior instrumentation & $22(100)$ & $38(100)$ & $6(100)$ \\
\hline Posterior decompression & $8(36.4)$ & $4(10.5)$ & $2(33.3)$ \\
\hline Cement augmentation & $0(0.0)$ & $9(23.7)$ & $2(33.3)$ \\
\hline Percutaneous instrumentation & $0(0.0)$ & $29(76.3)$ & $4(66.6)$ \\
\hline
\end{tabular}

strumentation is usually performed two levels above and below the fractured level. Additional ventral instrumentation by anterior cervical discectomy and fusion was performed in 5 patients. Anterior stabilization was a secondary procedure in 3 patients, providing additional stability in 2 patients ( 1 patient had a great intervertebral gap, and 1 had a dorsal screw explantation in revision), and performed for a prevertebral infection in 1 patient. Percutaneous instrumentation was performed in $75.0 \%$ of the patients with thoracic and lumbar fractures (Table 3).

\section{Clinical Outcome}

During hospitalization, $80.0 \%$ of patients developed complications. The 30-day mortality was $10.0 \%$, including 2 patients $(3.3 \%)$ who received best supportive care. The 30-day readmission rate was $5.0 \%$, with 1 patient incurring another spinal fracture (1.7\%) and 2 patients who had wound infections (3.3\%) (Table 4). The mean preoperative and postoperative overall intensive care unit stay was $5.5 \pm 11.2$ days (range $0-59$ days).

Surgical complications occurred in $18.3 \%$ of patients. Surgical revision was necessary in $13.3 \%$ of patients, with screw revision due to construct failure in 2 patients. Wound healing disorders, including wound infections, were reported in $8.3 \%$ of patients.

Due to multiple comorbidities requiring treatment during hospitalization, $76.7 \%$ of patients developed further medical issues, with pneumonia (38.3\%), pulmonary decompensation (25.0\%), and cardiac decompensation (20.0\%) being the leading causes (Table 4).

Regarding patient outcome, 5 patients improved in motor function postoperatively, whereas 2 patients deteriorated in motor function (Table 5). Four patients had improved ASIA grades postoperatively (Table 5). One patient showed trauma-related compression of both vertebral arteries and received best supportive care due to extensive cerebral ischemia.

\section{Discussion \\ General Aspects}

Fractures of ankylosing disease are complex, regarding patient characteristics, diagnostics, and surgical treatment. Patients with ASDs exhibit progressive kyphosis and an impaired muscle strength including the ability for com- 
TABLE 4. Postoperative complications

\begin{tabular}{|c|c|}
\hline & No. of Pts (\%) \\
\hline Overall no. of complications & $48(80.0)$ \\
\hline Surgical complications & $11(18.3)$ \\
\hline Surgical revision & $8(13.3)$ \\
\hline Rebleeding & $2(3.3)$ \\
\hline Construct failure & $4(6.7)$ \\
\hline latrogenic vertebral artery injury & $1(1.7)$ \\
\hline Completion after intraoperative reanimation & $1(1.7)$ \\
\hline Wound healing disorder & $5(8.3)$ \\
\hline Wound infection & $4(6.7)$ \\
\hline ICU treatment & $22(36.7)$ \\
\hline Systemic infections ${ }^{*}$ & $31(51.7)$ \\
\hline Blood stream infection & $9(15.0)$ \\
\hline Pneumonia & $23(38.3)$ \\
\hline UTI & $5(8.3)$ \\
\hline Decompensation of other medical issues & $42(70.0)$ \\
\hline Pulmonary decompensation & $15(25.0)$ \\
\hline Lung arteria embolism & $3(5.0)$ \\
\hline Cardiac decompensation & $12(20.0)$ \\
\hline Renal failure & $9(15.0)$ \\
\hline GI symptoms & $8(13.3)$ \\
\hline Additional medical issues $\dagger$ & $7(11.7)$ \\
\hline \multicolumn{2}{|c|}{$\begin{array}{l}\text { GI = gastrointestinal; ICU = intensive care unit; UTI = urinary tract infection. } \\
\text { * All infections requiring systemic antibiotic treatment, excluding wound } \\
\text { infections, were considered systemic infections. Wound infections are listed } \\
\text { separately in the group of wound healing disorders. } \\
\dagger \text { For example, deranged electrolytes and delirium. }\end{array}$} \\
\hline
\end{tabular}

pensation, which results in a poorer body balance and, therefore, an increased risk of falls. ${ }^{5,6}$ Furthermore, ectopic bone formation and reduced bone quality result in a further increased risk of fractures, ${ }^{1,4}$ studies have shown an increased risk of fractures and an 11.4 times increased risk of spinal cord injury. ${ }^{7}$ Older age and multiple comorbidities often requiring intensive medical care during hospitalization result in an overall increased perioperative risk.

Regarding the trauma mechanism, a majority of patients had only minor traumas like falls from a standing or sitting position. Hyperextension was the most frequent cause of trauma in this study, which also correlates with previous findings.

\section{Diagnostic Pitfalls}

On radiographic imaging, the increased vulnerability of the whole spine must be taken into consideration, with multilevel injuries occurring in $15.0 \%$ of patients in our study. Thus, diagnostics of the whole spine in patients with ASDs is required. ${ }^{8,9}$ In addition to CT scans, MRI is mandatory to further examine small fracture lines, prevertebral hematoma, nerve and spinal cord injury, and epidural hematoma. Until proven otherwise, patients with AS or DISH who fall should be considered to have sustained a spinal injury. ${ }^{10}$ Especially in patients who present with
TABLE 5. Patient outcomes according to the BMRC and ASIA grading systems

\begin{tabular}{|c|c|c|}
\hline & At Admission & At Discharge \\
\hline \multicolumn{3}{|l|}{ BMRC grade } \\
\hline 5 & $46(76.7)$ & $48(80.0)$ \\
\hline 4 & $4(6.7)$ & $4(6.7)$ \\
\hline 3 & $2(3.3)$ & $1(1.7)$ \\
\hline 2 & $3(5.0)$ & $3(5.0)$ \\
\hline 1 & $0(0.0)$ & $1(1.7)$ \\
\hline 0 & $5(8.3)$ & $2(3.3)$ \\
\hline \multicolumn{3}{|l|}{ ASIA grade } \\
\hline A & $3(5.0)$ & $4(6.7)$ \\
\hline$B$ & $1(1.7)$ & $1(1.7)$ \\
\hline C & $4(6.7)$ & $1(1.7)$ \\
\hline$D$ & $7(11.7)$ & $8(13.3)$ \\
\hline E & $45(75.0)$ & $46(76.7)$ \\
\hline 30-day mortality, \% & \multicolumn{2}{|c|}{10.0} \\
\hline 30 -day readmission, $\%$ & \multicolumn{2}{|c|}{5.0} \\
\hline
\end{tabular}

Values represent the number of patients (\%) unless indicated otherwise.

minor trauma and who are treated for syncopal events involving cardiopulmonary treatment, possible spinal injury must not be ignored. Additionally, prolonged time until diagnosis is a common issue among patients with AS.11,12 In our study, in $33 \%$ of patients from primary care centers, fractures were not correctly identified or only identified after a prolonged period of time. This correlates with findings from other trauma centers reporting rates of delayed diagnosis of up to $45 \% .^{13,14} \mathrm{~A}$ previous study on patients with AS found a delay in diagnosis in $17.1 \%$ of patients, with delay being related to both the treating physician and the patient seeking medical attention. ${ }^{15}$

\section{Surgical and Medical Complications}

Conservative fracture treatment is not recommended due the extensive mechanical instability resulting in a high risk of secondary spinal cord injury. ${ }^{16}$ For patients with a spinal cord injury, there is a significantly increased risk for complications and a prolonged hospital stay. ${ }^{17}$ Strict bedrest and en bloc mobilization are obligatory until surgical treatment.

Surgical treatment of fractures in patients diagnosed with ASDs is challenging. In general, surgery is limited by the multimorbidity of the patients and requires minimally invasive surgery with minimal blood loss and surgery duration. ${ }^{10,18,19}$ Ull et al. reported rates of chronic heart failure as high as $68.4 \%$ and a rate of chronic obstructive pulmonary disease of $30.5 \% .^{14}$ Intraoperative complications such as cardiac failure eventually leading to intraoperative reanimation must be considered.

Regarding anesthesia, a reduced mobility of the cervical spine often requires fiberoptic intubation or intubation by video laryngoscope. ${ }^{10,20}$ In addition to the challenging cardiac status of many of these patients, critical respiratory particularities of a rigid thorax and potentially preinjured lung due to trauma require experienced anesthe- 
siological staff. ${ }^{21,22}$ Yuksekkaya et al. analyzed CT scans obtained in patients with AS and found bronchiectasis in $51.2 \%$ and lung emphysema in $22.0 \%$ of the patients. ${ }^{22}$ Postoperative complications, including the extensive rate in our study of $38 \%$ of patients with postoperative pneumonia and $25 \%$ with pulmonary decompensation, must be considered (Table 4).

\section{Surgical Technique}

In fractures of the thoracolumbar spine, posterior-only instrumentation of three levels above and below the fracture level with or without additional decompression, is recommended ${ }^{8,16,18,23}$ (Fig. 1). When it comes to fractures of the cervical spine, anterior instrumentation alone is not sufficient, but regarding dorsal or combined dorsoventral instrumentation, the evidence is not clear and decisionmaking on a case-by-case basis is required. ${ }^{18,24}$ Yet, in patients with critical status, immediate anterior cervical surgery in the supine position can be an option for an initial safe and quick decompression. This is also represented in our data. Final fixation, however, then requires secondary posterior instrumentation.

Instrumentation should be performed percutaneously, especially when considering the high number of patients on regimens of antiplatelet agents (33.3\%) and oral anticoagulation. ${ }^{18,25,26}$ For improved stability of the construct, cement augmentation of the pedicle screws is recommended because of reduced bone quality. Yet, the rigid thorax, and therefore the problematic respiratory situation of these patients during pre- and postoperative care, needs to be taken into account because of the risks of cement embolism.

\section{Timing of Surgery}

Fractures in patients with AS show extensive mechanical instability resulting in a high risk of secondary spinal cord injury and, therefore, require urgent surgical treatment. In patients with neurological deficits, surgery should be performed without a time delay to prevent further neurological deterioration. However, patients with AS are at high risk due to multiple comorbidities, advanced age, and often-restricted cardiopulmonary capacity.$^{18}$ Furthermore, a majority of patients were on a regimen of antiplatelet agents and oral anticoagulation medications, resulting in increased intraoperative bleeding with increased intraoperative transfusion, and substitution of hemostatic agents and postoperative hematoma in cases of immediate surgery. In addition to that, only one case of neurological deterioration preoperatively, partially caused by patient noncompliance, was observed. This outlines that strict bedrest and en bloc mobilization are sufficient in most cases until surgery can be performed in an optimized setting.

\section{Conclusions}

Patients with ASDs must be treated with special care. They are at high risk of spinal injury after minor trauma, which requires thorough imaging of the entire spine. Fractures result in extensive instability and require percutaneous long-segment dorsal instrumentation. Patients and families need to be aware of the high perioperative medical complication rate including increased mortality due to the considerable comorbidities typical of this population. Treatment centers need to be capable of managing all upcoming medical or surgical events.

\section{Acknowledgments}

This trial was funded entirely by institutional grants from the Department of Neurosurgery, Technical University of Munich, Germany, School of Medicine, Klinikum rechts der Isar.

\section{References}

1. Kado DM, Browner WS, Palermo L, Nevitt MC, Genant HK, Cummings SR. Vertebral fractures and mortality in older women: a prospective study. Arch Intern Med. 1999;159(11): 1215-1220.

2. Kiss C, Szilágyi M, Paksy A, Poór G. Risk factors for diffuse idiopathic skeletal hyperostosis: a case-control study. Rheumatology (Oxford). 2002;41(1):27-30.

3. Mader R, Verlaan JJ, Buskila D. Diffuse idiopathic skeletal hyperostosis: clinical features and pathogenic mechanisms. Nat Rev Rheumatol. 2013;9(12):741-750.

4. Diederichs G, Engelken F, Marshall LM, Peters K, Black DM, Issever AS, et al. Diffuse idiopathic skeletal hyperostosis (DISH): relation to vertebral fractures and bone density. Osteoporos Int. 2011;22(6):1789-1797.

5. Murray HC, Elliott C, Barton SE, Murray A. Do patients with ankylosing spondylitis have poorer balance than normal subjects? Rheumatology (Oxford). 2000;39(5):497-500.

6. Heyde CE, Robinson Y, Kayser R, John T. Fatal complex fracture of the cervical spine in a patient with ankylosing spondylitis after a fall from a racing bicycle. Article in German. Sportverletz Sportschaden. 2007;21(3):148-151.

7. Alaranta H, Luoto S, Konttinen YT. Traumatic spinal cord injury as a complication to ankylosing spondylitis. An extended report. Clin Exp Rheumatol. 2002;20(1):66-68.

8. Reinhold M, Knop C, Kneitz C, Disch A. Spine fractures in ankylosing diseases: recommendations of the Spine Section of the German Society for Orthopaedics and Trauma (DGOU). Global Spine J. 2018;8(2)(suppl):56S-68S.

9. Geusens P, Vosse D, van der Linden S. Osteoporosis and vertebral fractures in ankylosing spondylitis. Curr Opin Rheumatol. 2007;19(4):335-339.

10. Chaudhary SB, Hullinger H, Vives MJ. Management of acute spinal fractures in ankylosing spondylitis. ISRN Rheumatol. 2011;2011:150484.

11. de Peretti F, Sane JC, Dran G, Razafindratsiva C, Argenson C. Ankylosed spine fractures with spondylitis or diffuse idiopathic skeletal hyperostosis: diagnosis and complications. Article in French. Rev Chir Orthop Reparatrice Appar Mot. 2004;90(5):456-465.

12. Bernstein DN, McCalla DJ, Molinari RW, Rubery PT, Menga EN, Mesfin A. An analysis of patient and fracture characteristics and clinical outcomes in patients with hyperostotic spine fractures. Global Spine J. 2020;10(8):964-972.

13. Kobayashi K, Okada E, Yoshii T, Tsushima M, Yamada $\mathrm{T}$, Watanabe K, et al. Risk factors for delayed diagnosis of spinal fracture associated with diffuse idiopathic skeletal hyperostosis: a nationwide multiinstitution survey. J Orthop Sci. Published online December 15, 2020. doi:10.1016/j. jos.2020.10.019

14. Ull C, Yilmaz E, Hoffmann MF, Reinke C, Aach M, Schildhauer TA, Kruppa C. Factors associated with major complications and mortality during hospitalization in patients with ankylosing spondylitis undergoing surgical management for a spine fracture. Global Spine J. Published online January 12, 2021. doi:10.1177/2192568220980702

15. Westerveld LA, Verlaan JJ, Oner FC. Spinal fractures in patients with ankylosing spinal disorders: a systematic review 
of the literature on treatment, neurological status and complications. Eur Spine J. 2009;18(2):145-156.

16. Caron T, Bransford R, Nguyen Q, Agel J, Chapman J, Bellabarba C. Spine fractures in patients with ankylosing spinal disorders. Spine (Phila Pa 1976). 2010;35(11):E458-E464.

17. Teunissen FR, Verbeek BM, Cha TD, Schwab JH. Spinal cord injury after traumatic spine fracture in patients with ankylosing spinal disorders. J Neurosurg Spine. 2017;27(6): 709-716.

18. Kurucan E, Bernstein DN, Mesfin A. Surgical management of spinal fractures in ankylosing spondylitis. J Spine Surg. 2018;4(3):501-508

19. Kiltz U, Sieper J, Braun J. Development of morbidity and mortality in patients with spondyloarthritis. Article in German. Z Rheumatol. 2011;70(6):473-479.

20. Schneider PS, Bouchard J, Moghadam K, Swamy G. Acute cervical fractures in ankylosing spondylitis: an opportunity to correct preexisting deformity. Spine (Phila Pa 1976). 2010; 35(7):E248-E252.

21. Kanathur N, Lee-Chiong T. Pulmonary manifestations of ankylosing spondylitis. Clin Chest Med. 2010;31(3):547-554.

22. Yuksekkaya R, Almus F, Celıkyay F, Celıkel S, Inanır A, Almus E, Ozmen Z. Pulmonary involvement in ankylosing spondylitis assessed by multidetector computed tomography. Pol J Radiol. 2014;79:156-163.

23. Krüger A, Frink M, Oberkircher L, El-Zayat BF, Ruchholtz $S$, Lechler P. Percutaneous dorsal instrumentation for thoracolumbar extension-distraction fractures in patients with ankylosing spinal disorders: a case series. Spine J. 2014; 14(12):2897-2904.

24. Werner BC, Samartzis D, Shen FH. Spinal fractures in patients with ankylosing spondylitis: etiology, diagnosis, and management. J Am Acad Orthop Surg. 2016;24(4):241-249.

25. Moussallem CD, McCutcheon BA, Clarke MJ, Cui Q, Currier BL, Yaszemski MJ, et al. Perioperative complications in open versus percutaneous treatment of spinal fractures in patients with an ankylosed spine. J Clin Neurosci. 2016;30:88-92.
26. Sedney CL, Daffner SD, Obafemi-Afolabi A, Gelb D, Ludwig S, Emery SE, France JC. A comparison of open and percutaneous techniques in the operative fixation of spinal fractures associated with ankylosing spinal disorders. Int $J$ Spine Surg. 2016;10:23.

\section{Disclosures}

Dr. Meyer received honoraria, consulting fees, and research grants from Medtronic, Icotec AG, and Relievant Medsystems Inc.; honoraria and research grants from Ulrich Medical; honoraria and consulting fees from Spineart Deutschland $\mathrm{GmbH}$ and DePuy Synthes; and royalties from Spineart Deutschland GmbH; and is a consultant for Medacta. Dr. Krieg is a consultant for Ulrich Medical and received honoraria from Nexstim Plc, Spineart Deutschland GmbH, Medtronic, and Carl Zeiss Meditec. Drs. Krieg and Meyer received research grants and are consultants for Brainlab AG.

\section{Author Contributions}

Conception and design: Krieg, Seule. Acquisition of data: Schwendner, Seule. Analysis and interpretation of data: Krieg, Schwendner, Seule. Drafting the article: Krieg, Schwendner. Critically revising the article: Krieg, Meyer. Reviewed submitted version of manuscript: Krieg, Meyer. Approved the final version of the manuscript on behalf of all authors: Krieg. Statistical analysis: Schwendner. Administrative/technical/material support: Krieg, Meyer. Study supervision: Krieg.

\section{Correspondence}

Sandro M. Krieg: Technische Universität München, Munich, Germany. sandro.krieg@tum.de. 